\title{
Ecoepidemiology and biology of Eratyrus mucronatus Stål, 1859 (Hemiptera: Reduviidae: Triatominae), a sylvatic vector of Chagas disease in the Brazilian Amazon
}

\author{
Gersonval Leandro Silva Monte ${ }^{[1]}$, Wanderli Pedro Tadei ${ }^{[1]}$ and Thaysa Marinho Farias ${ }^{[1]}$
}

[1]. Laboratório de Malária e Dengue, Departamento de Ciências da Saúde, Instituto Nacional de Pesquisas da Amazônia, Manaus, AM, Brasil.

\begin{abstract}
Introduction: Eratyrus mucronatus Stål, 1859 is a wild triatomine vector of Trypanosoma cruzi Chagas, 1909. However, little is known regarding the biology and ecoepidemiology of this triatomine in the Brazilian Amazon. The present study describes the biology of E. mucronatus grown under laboratory conditions and the epidemiological aspects of its natural breeding sites. Methods: Five colonies were monitored in the field for 3 years. Temperature and humidity measurements were taken in the mornings and afternoons at the natural breeding sites, and the behavior and distribution of the nymphs and adults were observed in the wild colony. We also monitored the life cycle under controlled laboratory conditions. Results: Some factors that were considered decisive for the establishment of these colonies were present at all of the colonies studied in the field. These factors included an active termite nest, a vertebrate for repast, and dry and shaded substrates with temperatures of $24-28^{\circ} \mathrm{C}$ and with humidity of $80-90 \%$. A generation was developed in 274 days under these microclimatic conditions in the laboratory. Conclusions: The climatic variables described in the field indicate that these environmental parameters have a limiting effect on the dispersal and colonization of E. mucronatus to new environments. In addition, the long period of development to adulthood demonstrates that only one generation can develop per year even under the more favorable laboratory conditions.
\end{abstract}

Keywords: Eratyrus mucronatus. Chagas disease. Ecoepidemiological. Biological cycle.

\section{INTRODUCTION}

The genus Eratyrus Stål, 1859 comprises only two species, Eratyrus cuspidatus and Eratyrus mucronatus; however, only E. mucronatus has been found in Brazil. Both species are considered sylvatic and potential vectors of Trypanosoma cruzi Chagas, $1909^{1,2}$. These insects are hematophagous throughout their developmental phases, are exopterygotes, and have a hemi-metabolic biological cycle, with the time gaps between each ecdysis conditioned to physiological and microclimatic variables. Experiments regarding the biology of certain triatomine species have revealed that their biological cycles vary from three to fifteen months $s^{3-5}$.

Triatomines occupy diverse natural ecotopes, such as mammal and bird nests, caves, palm trees, or rock fissures ${ }^{1}$. Studies $^{1,6}$ have shown that E. mucronatus is a sylvatic triatomine

\footnotetext{
Address to: Dr. Gersonval Leandro Silva Monte. Laboratório de Malária e Dengue/Depto. Ciências da Saúde/INPA. Rua B3, 1651, Conjunto 31 de Março, 69067-375 Manaus, AM, Brasil.

Phone: 5592 8136-0715

e-mail: gersonval.monte@inpa.gov.br

Received 29 October 2014

Accepted 15 December 2014
}

that is associated with the nests of Xenarthra, Didelphidae, and colonies of Chiroptera in tree hollows and caves. According to some authors ${ }^{2,7}$ E. mucronatus is also found in colonies with Triatoma maculata (a secondary vector of T. cruzi in Venezuela) and with Cavernicola pilosa (a vector of Schizotrypanum in bats and of T. cruzi).

Eratyrus mucronatus has been recorded in the Brazilian States of Amazonas, Pará, Goiás, Maranhão, Mato Grosso, and Rondônia ${ }^{8,9}$; however, intra-domiciliary colonization has not been recorded. In contrast, adult individuals have been captured outside and inside human dwellings in the rural areas of Manaus (author observation), and a few specimens were found to be naturally infected with $T$. cruzi; therefore, this species is likely to represent a T. cruzi transmission risk outside and inside human dwellings ${ }^{1,10}$.

Because E. mucronatus is primarily sylvatic, many studies pertaining to its biology and epidemiology are unavailable. With the exception of sporadic records regarding adults that are attracted to light sources in rural dwellings, few studies regarding the epidemiological importance of this species are available ${ }^{1,11,12}$.

Little is known regarding the ecoepidemiological characteristics of E. mucronatus because this species is essentially a sylvatic triatomine and because its colonies are difficult to locate and monitor in the field. Therefore, the present study aimed to describe some of the epidemiological aspects of E. mucronatus by characterizing its natural ecotype and biology under laboratory conditions. 


\section{METHODS}

The license for insect capture were issued by the Brazilian Institute of Environment and Renewable Natural Resources (IBAMA). IBAMA registration: 659216; holders: Wanderli Pedro Tadei and the Chico Mendes Institute for Biodiversity Conservation; license number: 175224-1.

This field study of E. mucronatus biology was conducted in the township of Coari, State of Amazonas on the right bank of the Urucu river [global positioning system (GPS) coordinates $\left.\mathrm{S} 4^{\circ} 53^{\prime} 7.33^{\prime \prime} / \mathrm{W} 65^{\circ} 20^{\prime} 59.99^{\prime \prime}\right]$. The region is covered by primary tropical rainforest and can be divided into floodplain and upland forest. The mean annual rainfall of this region is $2,239 \mathrm{~mm}$, and the mean temperature ranges from 25 to $26^{\circ} \mathrm{C}$ throughout the year ${ }^{13,14}$. This field work did not involve endangered or protected species, and no vertebrates were collected for this study.

We monitored five wild colonies from May 2010 to July 2013. Four of the colonies were on tanimbuca trees (Buchenavia sp.) (GPS coordinates: S04 ${ }^{\circ} 42^{\prime} 35.2^{\prime \prime} / \mathrm{W} 64^{\circ} 57^{\prime} 42.8^{\prime \prime}$, S04 $51^{\prime} 51.9^{\prime \prime} /$ W65 $20^{\prime} 12.4^{\prime \prime}, \mathrm{S}^{\circ} 4^{\circ} 52^{\prime} 50.2^{\prime \prime} / \mathrm{W} 65^{\circ} 17^{\prime} 24.7^{\prime \prime}$, and S04 $55^{\prime} 26.7^{\prime \prime \prime} /$ W65 $\left.{ }^{\circ} 19^{\prime} 36.9^{\prime \prime}\right)$, and one colony was on an angelinzeiro tree

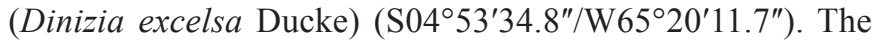
temperature and humidity of all of the colonies were measured in the morning and afternoon periods using a digital thermohygrometer suspended inside each colony 10 min before the measurement; this process was repeated for the outside of each colony. We measured the height and outer diameter of the colonized trees and the area holding the hollow where the colonies were found. All of the measurements were made using a Skil ${ }^{\circledR}$ laser point digital measurer and a manual tape measure. We made daily observations regarding the moving, foraging, and distribution of the nymphs and adults of each colony. The duration of each morning and afternoon observation was approximately $40 \mathrm{~min}$. Foraging situations and predator action on triatomines were recorded and photographed using a Panasonic digital camera (Lumix) DMC-FZ 18.

Three colonies that were composed of sylvatic specimens were collected in Coari to describe the biological cycle and vector potential of E. mucronatus. First and fifth-instar nymphs were collected from an unmonitored colony. The nymphs were transported in 50-ml filter paper-lined plastic pots. The pots were packed in a thermal box during transportation to the insectarium of the Triatominae, Phlebotominae, and Nidicola fauna of the INPA (Instituto National de Pesquisas da Amazônia).

The nymphs were transferred to $1-\mathrm{L}$ rearing pots at the insectarium. The bottoms of the pots were lined with filter paper and $10 \times 5$ centimeter tree bark slivers. Following the emergence of the imagos, three couples were separated to establish the experimental colonies. The colony pots were packed into a thermal box and maintained at a temperature of $26^{\circ} \mathrm{C}\left( \pm 2^{\circ} \mathrm{C}\right)$ and a relative atmospheric humidity of $90 \%( \pm 5 \%)$. The couples were monitored daily to verify egg laying. The eggs were placed individually in 2.5 - $\mathrm{ml}$ Eppendorf $₫$ tubes that contained slightly damp filter paper strips. This procedure allowed us to monitor egg incubation, determine the hatching percentage, and observed the death and ecdysis of the nymphs. When the nymphs reached the third instar phase, they were transferred to $100-\mathrm{ml}$ plastic vials until they reached the imaginal molting phase. We assessed the following parameters to identify the vector potential: the time required after birth to the attainment of the first meal, the duration of the instar phases, the mean adult life span, the time gap between the offering and the beginning of a meal, the meal duration, the time span from meal consumption to defecation, and starvation resistance.

\section{RESULTS}

\section{Eratyrus mucronatus ecoepidemiological characteristics}

The colonized trees were 20 to 30 meters in height and six to ten meters in diameter. The tree walls had many fissures and large active termite nests that had spread throughout most of the tree interior. The nymphs and adults were found scattered on either the surface or the interior of the fissures. When in close proximity to each other, the nymphs adopted an aggressive and territorial attitude by evicting the invader or raising the rostrum if an attempt was made on a meal. Each nymph had a thick dust cover for its mimicry of the environment (Figure 1).

Both nymphs and adults were distributed on an area that extended from approximately five centimeters above the soil up to three meters high and were always in the most active areas of the termite nests. Some first-instar nymphs were found inside the deep galleries of the termite nests and were engorged with hemolymph. During the 3-year study period, the density of triatomines was relatively stable at 5-13 individuals per colony tree. All of the individuals had little or almost no intestinal content. None of the nymph or adult triatomines was infected with T. cruzi; however, all of the adults were infected with gregarines in the hemolymph and gut.

Bats were found in the colony trees; we also recorded frogs (Dendrobatidae and Leptodactylidae) and lizards (Gekkonidae: Gonnatodes humeralis). In terms of the fauna of the arthropods, we recorded Ensifera, Blattaria, Hemiptera (Emesinae), Homoptera, Dermaptera, Coleoptera, Isoptera, Diptera (Phlebotominae), Hymenoptera, Trichoptera, Lepidoptera, Opiliones, Chilopoda, and Araneae. On one occasion, we observed a third-instar nymph being preyed upon by a spider (Salticidae) that approached the nymph with an armed rostrum (Figure 1).

The soil and surface of the walls inside the colonized trees remained dry throughout the study period; no infiltrations were observed even in the winter. The interior of the colonies maintained a mean humidity of $85 \%( \pm 5 \%)$ year-round; in the outer environment, the humidity was saturated every day during winter and fluctuated between $85 \%$ and $90 \%$ during summer. The mean temperature was $26^{\circ} \mathrm{C}\left( \pm 2^{\circ} \mathrm{C}\right)$ for the interior of the colonies and $25^{\circ} \mathrm{C}\left( \pm 5^{\circ} \mathrm{C}\right)$ for the outer environment.

\section{Biology in the laboratory}

The three colonies that were reared in the laboratory produced 292 eggs, with one female producing 130 of these eggs. All of the females began oviposition two weeks after 


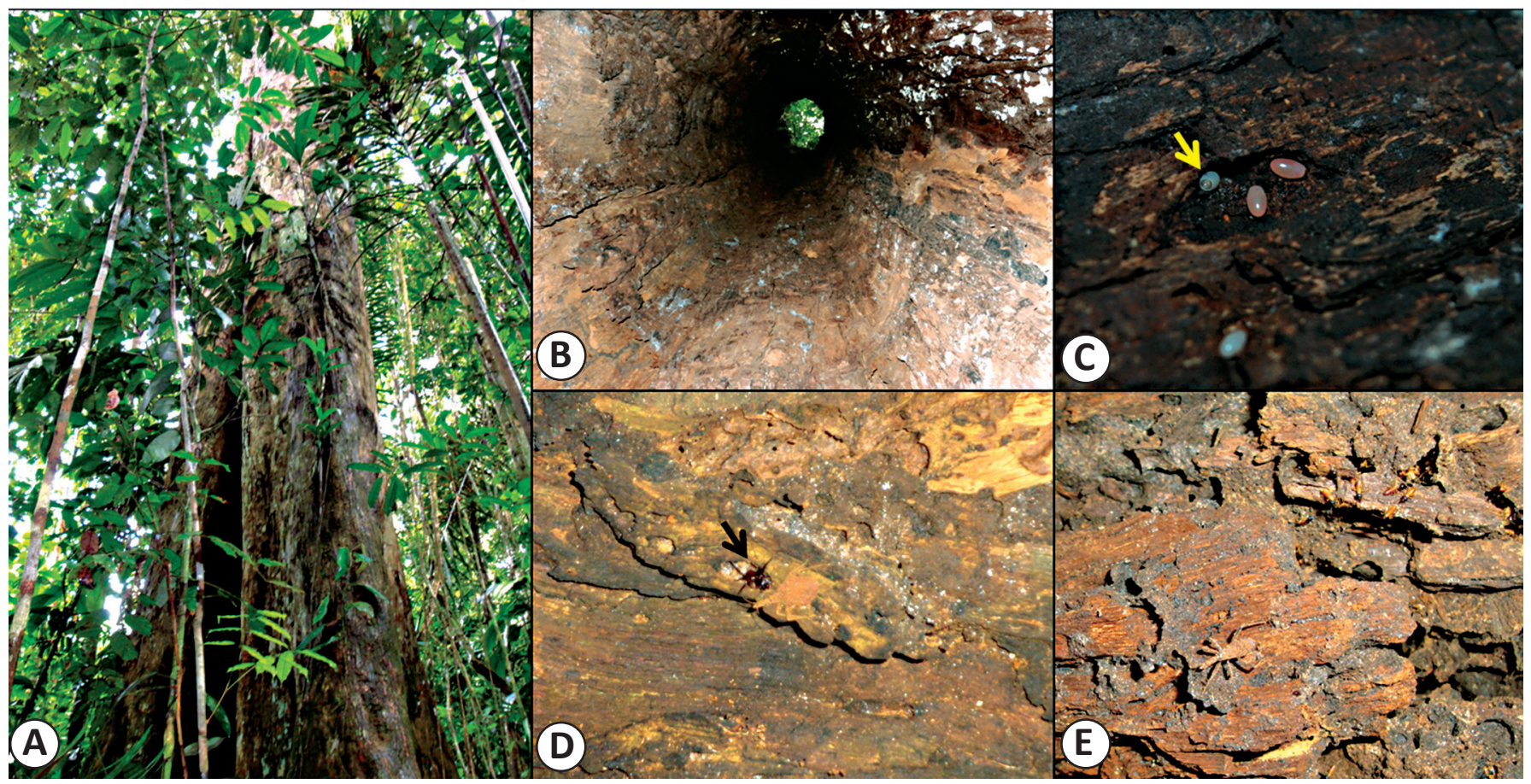

FIGURE 1 - Characteristics of the natural ecotope of Eratyrus mucronatus. A: Colony tree with a height of 30 meters and a diameter of eight meters; the entrance to the hollow tree was approximately three meters high and 60 centimeters wide. B: The walls inside the hollow tree had many fissures and an active termite mound spread across three or four meters in the interior of the colonized tree. C: Eggs found inside the galleries of the termite mound. Detail of the egg with open operculum (yellow arrow) and two embryonated eggs that were red. D: A third-instar nymph being preyed upon by a spider (black arrow). E: A third-instar nymph taken from a gallery of the active termite mound; is the nymph was covered with wood dust (bark-like camouflage).

the emergence of the adult phase and after a blood repast. The ovipositions were interspersed with several intervals of rest, and the longest recorded interval was 18 days. The ovipositions occurred in pairs or in groups of up to nine eggs in the crevices of the tree bark fragment placed inside the colony. The mean egg hatching period was 26 days, and the mean hatch rate was $21 \%$ (temperature, $26^{\circ} \mathrm{C}$; humidity, $90 \%$ ). The following two points were determined regarding the formation and success of the colonies: Total or partial permanence of the embrionary exuviae (proto-nymph exuviae) developed after the first-instar nymphs hatched and rejected food. The development time from first instar to imaginal molting occurred in 274 days (Table 1).

The nymphs consumed their first meal between the third and seventh day after hatching, with the greatest acceptance observed on the fifth day. All of the nymphal instars consumed at least three meals, although the females only fed once after the imaginal molt phase. Nymphs of E. mucronatus that consumed only one meal died without reaching the subsequent instar phase (Table 2).

The meal-defecation interval was observed for $15 \mathrm{~min}$. No correlation was observed between the amount of blood consumed and the occurrence of defecation. None of the nymphs or adults defecated during the 15-min observation period because the triatomines were fully engorged at every meal (Table 3).
TABLE 1 - Biological cycle durations (days) of Eratyrus mucronatus Stål, 1859 in the laboratory.

\begin{tabular}{lcccc}
\hline Instar & Min & Max & X & SD \\
\hline Egg - $1^{\circ}$ & 18 & 29 & 26 & 3 \\
$1^{\circ}-2^{\circ}$ & 21 & 48 & 36 & 10 \\
$2^{\circ}-3^{\circ}$ & 43 & 82 & 63 & 17 \\
$3^{\circ}-4^{\circ}$ & 48 & 70 & 66 & 13 \\
$4^{\circ}-5^{\circ}$ & 27 & 60 & 39 & 6.2 \\
$5^{\circ}-$ imago & 31 & 56 & 44 & 8.2 \\
\hline Total & 188 & 345 & 274 & \\
\hline
\end{tabular}

Min: minimum; Max: maximum; X: mean; SD: standard deviation.

\section{DIscussion}

Gregarious behavior was not observed in E. mucronatus at any time; this observation is unlike synanthropic triatomines but is characteristic of Triatoma infestans and Triatoma sordida ${ }^{15}$. The colonies were not visited by rats, Didelphidae, monkeys, or other mammals because no traces of feces or nests were observed. The presence of bats may explain the blood in the intestinal contents of the triatomines. The association of bats with $E$. mucronatus was first reported by Lent and Wygodzinsky in $1979^{1}$. 
TABLE 2 - Time gap between the meal offer and its acceptance in Eratyrus mucronatus Stål, 1859 in the laboratory.

\begin{tabular}{lcccc}
\hline Instar & Min & Max & X & SD \\
\hline $\mathrm{N} 1^{\circ}$ & $00: 00$ & $23: 45$ & $07: 10$ & $09: 06$ \\
$\mathrm{~N}^{\circ}$ & $00: 09$ & $24: 32$ & $09: 50$ & $09: 04$ \\
$\mathrm{~N}^{\circ}$ & $01: 21$ & $25: 17$ & $11: 00$ & $10: 07$ \\
$\mathrm{~N}^{\circ}$ & $00: 04$ & $24: 54$ & $14: 00$ & $10: 09$ \\
$\mathrm{~N}^{\circ}$ & $00: 00$ & $23: 52$ & $13: 02$ & $10: 00$ \\
Adult & $03: 36$ & $28: 07$ & $13: 04$ & $09: 06$ \\
\hline
\end{tabular}

Min: minimum; Max: maximum; X: mean; SD: standard deviation.

TABLE 3 - Meal durations and meal-defecation intervals ( $\min )$ in instars of Eratyrus mucronatus Stål, 1859.

\begin{tabular}{lccccc}
\hline Instar & Min & Max & X & SD & Meal defecation \\
\hline $\mathrm{N} 1^{\circ}$ & 5 & 46 & 14 & 8.56 & $>15$ \\
$\mathrm{~N} 2^{\circ}$ & 5 & 25 & 17 & 5.92 & $>15$ \\
$\mathrm{~N}^{\circ}$ & 6 & 14 & 10 & 2.85 & $>15$ \\
$\mathrm{~N}^{\circ}$ & 8 & 41 & 24 & 11.1 & $>15$ \\
$\mathrm{~N}^{\circ}$ & 13 & 42 & 21 & 11.22 & $>15$ \\
Adult & 11 & 29 & 18 & 9.64 & $>15$ \\
\hline
\end{tabular}

Min: minimum; Max: maximum; X: mean; SD: standard deviation.

The few vertebrates found living with the colonies of E. mucronatus acts as a limiting factor for the number of triatomine insects, which explains few observed individuals per colony and the presence of first- and second-instar nymphs scattered throughout the galleries of the termite mounds. The latter observation demonstrates the opportunistic nature of these triatomines, where the nymphs performed hemolymphagy on termites and other arthropods present in the termite mound. Hemolymphagy has also been observed in other triatomines, such as Triatoma rubrovaria, Rhodnius brethesi, and Belminus herreri $i^{16,17,18}$. The microclimatic parameters that were measured in the interior of the colonies demonstrated little intrinsic variation throughout the year, which appears to be independent of the variations in the outer temperature and humidity. The climatic variables in temperature and humidity observed in the field indicate that these environmental parameters limit the dispersal and colonization of E. mucronatus to new environments. The long period of development to adulthood demonstrates that only one generation can develop per year even under the more favorable laboratory conditions. Long developmental periods have been described in other species, including $R$. brethesi, with 115 days $^{5}$; Triatoma pseudomaculata, with 398 days $^{4}$; and T. rubrovaria, with 358 days $^{19}$.

Unlike other triatomine species in which only one meal is sufficient to reach the subsequent instar phase $\mathrm{e}^{5,20}$, the
E. mucronatus nymphs that consumed only one meal died without reaching the subsequent instar phase. The time gap between the meal offering and its acceptance may provide insight into the voraciousness of the triatomine in seeking food ${ }^{21}$.

The meal-defecation interval was observed for $15 \mathrm{~min}$, with no correlation observed between the amount of blood consumed and the occurrence of defecation. None of the nymphs or adults defecated during the 15-min observation period because the triatomines were fully engorged at every meal.

The observed meal durations and meal-defecation intervals during all developmental cycle phases are key parameters for determining the vector potential of a triatomine $\mathrm{e}^{22}$. We used a 15min period to observe the meal-defecation interval; this interval is longer than the periods used in other studies ${ }^{4,5}$ because we believed that this interval would provide sufficient time for this sylvatic species (with little known biology) to leave its host and to seek shelter after ending its meal. No correlation was observed between the amount of blood consumed and the occurrence of defecation. None of the nymphs or adults defecated during the 15-min observation period because the triatomines were fully engorged at every meal. These results, together with our findings that none of the triatomines found in the colony trees were infected with $T$. cruzi, suggest that the E. mucronatus species found under these bioecological conditions of the Brazilian Amazon is not a good vector for T. cruzi. However, an infection in the triatomine cannot be excluded if this organism has fed on infected mammals.

\section{ACKNOWLEDGMENTS}

We thank João Bosco for his support during the field work.

\section{CONFLICT OF INTEREST}

The authors declare that there is no conflict of interest.

\section{FINANCIAL SUPPORT}

Gersonval Leandro Silva Monte has a fellowship from Institucional do Ministério da Ciência e Tecnologia.

\section{REFERENCES}

1. Lent H, Wygodzinsky P. Revision of the triatominae (Hemiptera, Reduviidae) and their significance as vectors of Chagas disease. Bull Am Mus Nat His New York 1979; 163:123-520.

2. Guerrero L, Scorza JV. Las fuentes alimenticias de algunos Triatominae silvestres en los llanos centro occidentales de Venezuela. Bol Dir Malariol y San Amb 1981; 21:129-139.

3. Diotaiuti L, Dias JCP. Estudo comparativo do ciclo evolutivo de Rhodnius neglectus alimentados em pombos ou camundongos. Rev Soc Bras Med Trop 1987; 20:95-100.

4. Gonçalves TCM, Cunha V, Oliveira E, Jurberg J. Alguns aspectos da biologia de Triatoma pseudomaculata Corrêa and Espínola, 1964 em condições de laboratório (Hemiptera: Reduviidae: Triatominae). Mem Inst Oswaldo Cruz 1997; 92:275-280. 
5. Rocha DS, Santos CM, Cunha V, Jurberg J, Galvão C. Ciclo biológico em laboratório de Rhodnius brethesi Matta, 1919 (Hemiptera, Reduviidae, Triatominae), Potencial vetor silvestre da Doença de Chagas na Amazônia. Mem Inst Oswaldo Cruz 2004; 99:591-595.

6. Gaunt M, Miles M. The ecotopes and evolution of triatominae bugs (triatominae) and their associated trypanosomes. Mem Inst Oswaldo Cruz 2000; 95:557-565.

7. Dias E, Mello GB, Costa O, Damasceno RG, Azevedo M. Investigações sobre esquisotripanose de morcegos no estado do Pará. Encontro do barbeiro "Cavernicola pilosa" como transmissor. Rev Bras Bio 1942; 2:103-110.

8. Galvão C, Carcavallo R, Rocha DS, Jurberg J. A checklist of the current valid species of the subfamily Triatominae Jeannel, 1919 (Hemiptera: Reduviidae) and their geographical distribution, with nomenclatural and taxonomic notes. Zootaxa 2003; 202:1-36.

9. Meneguetti DUO, Trevisan O, Rosa RM, Camargo LMA. First report of Eratyrus mucronatus, Stal, 1859, (Hemiptera: Reduviidae: Triatominae), in the State of Rondônia, Brazil. Rev Soc Bras Med Trop 2011; 44:511-512.

10. Sherlock I, Carcavallo R, Galíndez I. List of natural and experimental flagellate infections in several triatominae species. In: Carcavallo R, Galíndez I, Jurberg J, Lent H, editors. Atlas of Chagas'Disease Vectors in the Americas. Vol. II. Rio de Janeiro: Editora FIOCRUZ; 1997. p. 289-297.

11. Naiff MF, Naiff RD, Barrett TV. Vetores selváticos de doença de Chagas na área urbana de Manaus (AM): atividade de voo nas estações secas e chuvosas. Rev Soc Bras Med Trop 1998; 31: 103-105.

12. Castro MC, Barrett TV, Santos WS, Abad-Franch F, Rafael JA. Attraction of Chagas disease vectors (Triatominae) to artificial light sources in the canopy of primary Amazon rainforest. Mem Inst Oswaldo Cruz 2010; 105:1061-1064.

13. Amaral IL. Floristic diversity in upland forest, in Urucu region - AM. [Masters Dissertation]. [Manaus]: Instituto Nacional de Pesquisas da Amazônia. Fundação Universidade do Amazonas; 1996.

14. Teixeira WG, Cruz MEG, Martins GC, Macedo RS, Correia MR, Lima HN, et al. Survey of pedology bases available to the Coari municipality - AM. II Workshop de avaliação técnica e científica Rede CT-PETRO Amazônia; 2006.

15. Bar ME, Oscherov EB, Damborsky MP, Porcel EA, Alvarez BM. Interacción entre poblaciones de Triatoma infestans y Triatoma sordida. Rev Saúde Pública. São Paulo 1994; 28:59-68.

16. Miles MA, Souza AA, Povoa M. Chagas' disease in the Amazon basin III. Ecotopes of ten triatominae bug species (Hemiptera: Reduviidae) from the vicinity of Belém, Pará State, Brazil. J Med Entomol 1981; 18:266-278.

17. Mascarenhas BM. Triatomíneos da Amazônia: sobre o habitat e algumas considerações comportamentais de Rhodnius brethesi Matta, 1919 (Hemiptera: Reduviidae: Triatominae) na região do médio Rio Negro, Amazonas. Bol Mus Par Emilio Goeldi Série Zol 1991; 7:107-116.

18. Sandoval CM, Duarte R, Gutierrez R, Rocha DS, Angulo VM, Esteban L, et al. Feeding sources and natural infection of Belminus herreri (Hemiptera: Reduviidae: Triatominae) from dwellings in Cesar, Colombia. Mem Inst Oswaldo Cruz 2004; 99:137-140.

19. Argüello NV, Mischis CC, Civitta G, Bonino EE. Ciclo biológico de Triatoma Rubrovaria (Blanchard) (Reduviidae, Triatominae) em laboratório. Rev Bras Zool 1988; 5:245-251.

20. Brasileiro VLF, Perondini ALP. Biologia do Triatoma brasiliensis (Hemiptera: Reduviidae: Triatominae) 1. Tempo de sucção e repleção de ninfas de $4^{\circ}$ e $5^{\circ}$ estádio. Rev Bras Ent 1974; 18:43-50.

21. Gonçalves TCM, Victório VMN, Jurberg J, Cunha V. Biologia do Triatoma vitticeps (Stal, 1859) em condições de laboratório (Hemiptera: Reduviidae: Triatominae). I. Ciclo evolutivo. Mem Inst Oswaldo Cruz 1988; 83:519-523.

22. Piesman J, Sherlock LA. Factors controlling the volume produced by triatominae vectors of Chagas' disease. Acta Trop 1983; 40:351-358. 